\title{
Correspondence
}

\section{Citation Idiosyncrasies}

SIR,-In continuing the discussion on the use of the Science Citation Index for historical purposes, $\mathrm{Mr}$ Cawkell is undoubtedly right in arguing that it is necessary to work on probabilities rather than certainties. You, sir, are equally correct in your editorial in pointing out that comparatively little is known as to why authors cite particular papers when writing an account of their own work.

In my review of the Science Citation Index for 1964 (Nature, 208, 717; 1965) I made two particular points. First, that the value of the Index could only be truly assessed when volumes covering a number of years were available. That is now the situation, and it is reasonable to say that it has proved to be a useful information retrieval tool. As a generalization it can be said that, if the use of any major information retrieval system results in the retrieval of some 60 per cent of the relevant papers (for example, ref. 1), then the Science Citation Index will also be able to produce references to some 60 per cent of the relevant papers; the value of the index is that it is likely to retrieve a different sub-set and therefore the use of the two systems might well result in an increase of, say, 85 per cent in the overall recall ratio.

My second point was that an improvement in the citing habits of authors would do more than anything else to improve the usefulness of a citation index, and suggested that the time was coming when editors of scientific journals should take the same active steps to obtain a higher quality of citing as they have successfully been doing in relation to titles and abstracts. While the ultimate value of citation indexes was still uncertain, this was perhaps an optimistic hope, but the adoption of a simple code showing the purpose of a citation, for example, that it referred to a standard experimental technique, would undoubtedly increase the usefulness of the Science Citation Index. It would not, of course, result in the retrieval of a single additional relevant paper, but it would eliminate some of the noise which, pace Mr Cawkell's remarks, is as troublesome in the Science Citation Index as in any other information retrieval system.

$$
\text { Yours faithfully, }
$$

\section{W. Clevverdon}

Library,

Cranfield Institute of Technology,

Cranficld, Bedford.

${ }^{2}$ Lancaster, F. W., Evaluation of the Medlurs Demand Search Service (National Library of Medicine, Washington, 1968)

SrR,--The recent correspondence in Nature on tho importance or otherwise of having one's papers cited extensively and the alleged structure of scientific dovelopment which can be perceived in a citation index has led. me to wonder whether reference giving has not become an absurd convention which scientists unthinkingly adhere to. I claim no special virtue of freedom from infection in this respect.

To the outsider, the scientific referencing system must seem burdensome, pompous and irrelevant. What is the purpose of giving a reference? We answer that it allows the reader to enter a new field by giving him background, that it establishes the truth of our assertions and it enables us to indicate the extent of our own original contribution. Our rationalized view of reference-giving seems to me about as relevant to what really happens in science as the philosopher of science's concern with induction, deduction, hypothesis theory and law. The process of giving a reference is frequently wayward, dishonest or self-centred. We are fairly well constrained to tell the truth so all our pent-up human instinct to self aggrandisement comes bubbling to the surface in those first few paragraphs where we tell it "like it is". In that fertile ground we can tell you how we had the idea first"The recent interesting proposal of Doe et al." comes as a gratifying confirmation of my earlier ideas ${ }^{2}$ ", where it turns out that reference ( 1 ) is a full mathematical analysis with several experimental examples whereas (2) is the abstract of a speculative paper read to the Bruddesford Philosophical Society in which we managed to cover all possible developments in half an hour of arm-waving. Or we can tell you how extraordinarily well read we are, by quoting fifteen peripherally relevant articles in fifteen languages. Most of these articles will have been accumulated by accretion. Someone else referred to them and we added them to our list because they looked nice. This illustrates a fundamental law of reference giving-it is quite unnecessary to have read or even seen the reference yourself before quoting it.

Or we can show how up-to-date we are with all our references being not more than two years old. Or we can show how well connected we are by giving references to a large number of preprints. Or we can discreetly kick someone in the teeth by omitting to refer to his relevant paper. This last procedure guarantees us a large manilla envelope in the mail a few weeks later with his reprint inscribed with compliments. Or we can show our con. tempt for modern science by referring only to textbooks printed before 1900 . Or we can spike criticism by a glowing reference to a potential critic. Or (the most common of all) we can tako out our box of well-worn cards, shuffle them, xerox them and stick them on the end of the paper. "A mere orgy of dittography" as Evelyn Waugh's headmaster once criticized one of his essays. But we must be careful to mention every reference in the text; one of the more common sub-editorial comments on galley proofs is "not mentioned in text" against references.

With such an idiosyncratic background to references, why bother at all ? Practising insiders know how a paper fits into the mainstream of science and references are wasted on them. The intelligent outsider, if he can ever wade through our prose, is presumably sufficiently intelligent to write to us if he wants to know more. Perhaps most persuasive, however, is the time that would be saved by secretaries, sub-editors and printers in not having to reproduce that page of staccato, italicized, underlined, abbreviated, semi-colonized non-prose. And not having to worry whether the abbreviation for "Royal" if roy. or Roy. or even $r$.

As you must be aware, sir, authors of articles in Nature deem it desirable to have $25 \pm 10$ references in their papers. By reducing references to mention of previously unnoticed papers, useful equations and proofs, papers which one takes issue with or papers of very recent vintage which need to be brought urgently to public attention this figure might be reduced to $5 \pm 3$. It does not seem to me that science would be impeded; some money might even be saved.

I repeat - mea culpa, sed inter alios.

Yours faithfully,

47 Cross Street,

David Davies

Belmont,

Massachusetts 02178. 